\title{
Hypoglycemic and Hypolipidemic Effects of Melastoma dodecandrum ethanol-extract on Type 2 Diabetic Rats
}

\author{
Chang-Lei LI ${ }^{1}$, Bao-Miao MA², Xiao-Qing CHEN ${ }^{1}$, Yu-Wei LIU ${ }^{1}$, Xi-Ji SHU ${ }^{1, *}$ \\ ${ }^{1}$ School of Medicine, Jianghan University, Wuhan 430056, China \\ ${ }^{2}$ Wuhan Institutes of Biomedical Sciences, Jianghan University, Wuhan 430056, China \\ * Corresponding author:email: shuxiji@sina.com
}

Keywords: Melastoma dodecandrum ethanol-extract, type 2 diabetics, blood glucose, blood lipid

\begin{abstract}
To observe hypoglycemic and hypolipidemic effects of Melastoma dodecandrum ethanol-extract on type 2 diabetic rats. Except twelve SPF SD rats were as the control group, the rest eighty type 2 diabetic rats were induced by feeding with high-fat and high-sugar diet and intraperitoneal injection of low-dose streptozotocin $\left(\mathrm{STZ}, 35 \mathrm{mg} \cdot \mathrm{kg}^{-1}\right.$ ). According to the values of blood glucose concentration $\left(\geqq 11.1 \mathrm{mmol} \cdot \mathrm{L}^{-1}\right)$, the rats were randomly divided into diabetic model group, three Melastoma dodecandrum ethanol-extract groups of high dose $\left(40 \mathrm{~g} \cdot \mathrm{kg}^{-1}\right)$, medium dose $\left(20 \mathrm{~g} \cdot \mathrm{kg}^{-1}\right)$ and low dose $\left(10 \mathrm{~g} \cdot \mathrm{kg}^{-1}\right)$, and positive control group (glibenclamide, $\left.0.30 \mathrm{mg} \cdot \mathrm{kg}^{-1}\right)$. During $36 \mathrm{~d}$ of continuous intragastric (ig) administration, body weights of the rats were measured weekly, the values of fasting blood glucose (FBG) concentration were measured on 7, 14, 21, 28, $35 \mathrm{~d}$ after administration. After the last administration, fasting $10 \mathrm{~h}$, then, the rats were decapitated after anesthesia. Blood of the rats were collected for the analysis of serum insulin(INS), total cholesterol(TC), triglycerides(TG) and low density lipoprotein (LDL-C) levels. Compared with the control group, FBG of model group rats were significantly increased $(P<0.01)$. After administration $21 \mathrm{~d}$, compared with the model group, FBG of Melastoma dodecandrum ethanol-extract groups of high dose and medium dose were significantly lower $(P<0.01$ or 0.05$)$; after administration $28 \mathrm{~d}$, compared with the model group, FBG of Melastoma dodecandrum ethanol-extract groups of high dose, medium dose, low dose and positive control group were significantly lower $(P<0.01$ or 0.05$)$. Compared with the control group, INS levels of model group were significantly lower $(P<0.01)$; compared with the model group, INS levels of Melastoma dodecandrum ethanol-extract medium dose group were significantly increased $(P<0.05)$. Compared with the control group, TC, TG and LDL-C levels of model group rats were significantly increased $(P<0.01)$, TG of positive control group was significantly increased $(P<0.05)$. Compared with the model group, TC and LDL-C levels of Melastoma dodecandrum ethanol-extract medium dose group were significantly lower $(P<0.05)$ and TG levels was significantly lower $(P<0.01)$; TG levels of positive control group was significantly lower $(P<0.01)$. Melastoma dodecandrum ethanol-extract can decrease blood glucose, regulate blood lipids in type 2 diabetic rats.
\end{abstract}

\section{Introduction}

Melastoma dodecandrum is the dried whole plants, which mainly grows in Zhejiang, Fujian, Guangdong, Guangxi, Guizhou and so on. Taste sweet, astringent and potency cool. Attributed to heart, liver, spleen and lung. It's function was detoxification, expelling wind and dampness, blood hemostasis. Clinically for treatment some diseases, such as fever, lung abscess, swollen throat, toothache, and so on. The studied results shown that Melastoma dodecandrum contains a variety of chemical constituents, such as polysaccharides, flavonoids, amino acids, pigments, etc, which has some efficacies for anti-tumor, anti-aging, decrease blood glucose and regulate blood lipids and so on $^{[1,2,3]}$. Researchers found that Melastoma dodecandrum ethanol-extract can decrease blood glucose for alloxan-induced diabetic mice, and also showed that significant hypoglycemic effect for diabetic model mice whom caused by glucose, adrenaline and streptozotocin ${ }^{[4,5]}$, but some reports about effects of melastoma dodecandrum ethanol-extract on type 2 diabetic rats not yet found. In this study, 
through observed some changes for weight, FBG, INS, TC, TG and LDL-C content of type 2 diabetic model rats whom be used Melastoma dodecandrum ethanol-extract, discussion the pharmacological effects about Melastoma dodecandrum ethanol-extract on type 2 diabetic rats.

\section{Materials and methods}

Animals. A total of 92 SPF SD rats, half of each are male and female, and their body weight were $200 \pm 20 \mathrm{~g}$, whom were conventional breed in barrier environment, eating and drinking with free state. Water and feed were irradiation and sterilized by ${ }^{60} \mathrm{Co}, 12 \mathrm{~h} / 12 \mathrm{~h}$ dark cycle ${ }^{[6]}$.

Reagents and instruments. Melastoma dodecandrum were dry grass which provided by school of medicine. Herbs be put into the $95 \%$ ethanol soaked overnight, heating and extracted three times, each time for $1 \mathrm{~h}$, filtered and combined filtrate which recycled and concentrated until no alcohol taste under the reduced pressure, obtained dark green extract which be alternated ${ }^{[5]}$.

Streptozotocin, meter, glucose, glyburide, insulin radioimmunoassay kit, total cholesterol assay kit, glycated serum protein assay kit, triglyceride detection kit, low density lipoprotein test kit and so on.

Modeling and packet administration. Rats be randomized after suitability feeding for a week, control group rats were 12 whom be fed normal diet, and to be made in the model group rats were 80 whom be fed high-fat and high-sugar diet. After the rats were fed four weeks, intraperitoneal injection the STZ for $35 \mathrm{mg} \cdot \mathrm{kg}^{-1}$ which be used to make the model ${ }^{[7]}$. STZ contains citric acid and sodium citrate buffer solution (PH4.4) and the ratio was 1:1.32 ${ }^{[8]}$. Rats were not prohibit drinking but fasted for $12 \mathrm{~h}$ before intraperitoneal injection the STZ, the values of FBG concentration were measured on $96 \mathrm{~h}$ after administration. The success criteria of type 2 diabetic model rats is the blood glucose level $\geqq 11.1 \mathrm{mmol} \cdot \mathrm{L}^{-1[9,10]}$. After testing, a total of 66 rats were produced model with successfully, the blood sugar of control group rats were normal.

After the models were made with successfully, according to the values of FBG concentration, the rats were randomly divided into diabetic model group, three Melastoma dodecandrum ethanol-extract groups of high dose, medium dose and low dose, and positive control group (glibenclamide), the number of each group is 12. Rats in each group be continued to give high-fat and high-sugar diet for two weeks in order to consolidate the model. Initiation of administration after the model was made with successfully, control group and diabetic model group be given saline with $20 \mathrm{ml} \cdot \mathrm{kg}^{-1}$, positive control group be given glibenclamide with $0.30 \mathrm{mg} \cdot \mathrm{kg}^{-1}$, three Melastoma dodecandrum ethanol-extract groups of high dose, medium dose and low dose be given ethanol-extract with $40 \mathrm{~g} \cdot \mathrm{kg}^{-1}, 20 \mathrm{~g} \cdot \mathrm{kg}^{-1}, 10 \mathrm{~g} \cdot \mathrm{kg}^{-1}$ respectively, intragastric administration once per day and continued for $36 \mathrm{~d}$, during this time, the rats of each group no death. After the last administration, fasting $10 \mathrm{~h}$, the rats were decapitated after anesthesia with $10 \%$ chloral hydrate in $3 \mathrm{ml} \cdot \mathrm{kg}^{-1}$ and collected blood, the blood were put into the centrifuge with 3500 revolutions per minute and work for $10 \mathrm{~m}$, erum of the rats were collected for the detection and analysis.

Detection indicators. During $36 \mathrm{~d}$ of continuous administration, body weights of the rats were measured weekly. The values of FBG concentration were measured by using the Sino blood glucose meter on 7, 14, 21, 28, $35 \mathrm{~d}$ after administration. Follow the instructions to detect the INS content. According to the enzyme assay to detect the TG and TC of serum. By using SUR method to detect the LDL-C.

Statistical Analysis. Using SPSS 13.0 software for statistical analysis of the obtained data, the results of the indicators were expressed by $\mathrm{x} \pm \mathrm{s}$, significance test using the $\mathrm{t}$ test and ANOVA. With $P<0.05$ was considered statistically significant and $P<0.01$ as statistically significant difference.

\section{Results}

Body weight effects of Melastoma dodecandrum ethanol-extract on type 2 diabetic rats. Compared with the control group, body weight of model group rats were significantly lower $(P<0.01)$. Body weight gradually decreased of rats with Melastoma dodecandrum ethanol-extract of medium 
dose group, compared with the control group, body weight of rats significantly lower at 1st and 2nd week $(P<0.05)$, beginning from 3rd week, body weight of rats significantly lower $(P<0.01)$; compared with the model group, body weight of rats significantly increased $(P<0.05)$. Shown in table 1.

Table 1 Body weight effects of Melastoma dodecandrum ethanol-extract on type 2 diabetic rats $(\mathrm{x} \pm \mathrm{s})$

\begin{tabular}{|c|c|c|c|c|c|c|c|}
\hline \multirow{2}{*}{ Groups } & \multirow{2}{*}{$\mathrm{n}$} & \multirow{2}{*}{$\begin{array}{l}\text { Dose } \\
\mathrm{Ig} \cdot \mathrm{kg}^{-1}\end{array}$} & \multicolumn{5}{|c|}{ Weight / g } \\
\hline & & & 1st wk & 2nd wk & 3rd wk & 4th wk & 5th wk \\
\hline control group & 12 & - & $413 \pm 27$ & $428 \pm 31$ & $455 \pm 30$ & $439 \pm 32$ & $427 \pm 29$ \\
\hline model group & 12 & - & $309 \pm 38^{b}$ & $295 \pm 35^{b}$ & $277 \pm 33^{b}$ & $256 \pm 36^{b}$ & $241 \pm 30^{b}$ \\
\hline $\begin{array}{l}\text { Melastoma } \\
\text { dodecandrum }\end{array}$ & 12 & 10 & $305 \pm 48$ & $318 \pm 42$ & $326 \pm 40$ & $311 \pm 43$ & $307 \pm 41$ \\
\hline ethanol-extract & 12 & 20 & $342 \pm 25^{\mathrm{a}, \mathrm{c}}$ & $333 \pm 29^{a, c}$ & $328 \pm 31^{\mathrm{b}, \mathrm{c}}$ & $314 \pm 30^{\mathrm{b}, \mathrm{c}}$ & $309 \pm 26^{b, c}$ \\
\hline & 12 & 40 & $329 \pm 34$ & $318 \pm 40$ & $323 \pm 36$ & $307 \pm 29$ & $289 \pm 33$ \\
\hline control group & 12 & $0.30 \times 10^{-3}$ & $315 \pm 29$ & $311 \pm 31$ & $301 \pm 30$ & $298 \pm 27$ & $281 \pm 36$ \\
\hline
\end{tabular}

Note: compared with the control group, ${ }^{\mathrm{a}} P<0.05,{ }^{\mathrm{b}} P<0.01$; compared with the model group, ${ }^{\mathrm{c}} P<0.05,{ }^{\mathrm{d}} P<0.01$ (Table 2 and table 3 as the same as table 1 )

FBG effects of Melastoma dodecandrum ethanol-extract on type 2 diabetic rats. Compared with the control group, FBG of model group rats were significantly increased $(P<0.01)$. After administration 21d, compared with the model group, FBG of Melastoma dodecandrum ethanol-extract groups of high dose and medium dose were significantly lower $(P<0.01$ or 0.05$)$; after administration $28 \mathrm{~d}$, compared with the model group, FBG of Melastoma dodecandrum ethanol-extract groups of high dose, medium dose, low dose and positive control group were significantly lower $(P<0.01$ or 0.05$)$. Shown in table 2 .

INS effects of Melastoma dodecandrum ethanol-extract on type 2 diabetic rats. Compared with the control group, INS levels of model group were significantly lower $(P<0.01)$. Compared with the model group, INS levels of Melastoma dodecandrum ethanol-extract medium dose group were significantly increased $(P<0.05)$. Shown in table 2 .

Table 2 FBG and INS effects of Melastoma dodecandrum ethanol-extract on type 2 diabetic rats ( $\mathrm{x}_{\mathrm{x}} \pm$ )

\begin{tabular}{|c|c|c|c|c|c|c|c|c|}
\hline \multirow{2}{*}{ Groups } & \multirow{2}{*}{$\mathrm{n}$} & \multirow{2}{*}{$\begin{array}{l}\text { Dose } \\
/ \mathrm{g} \cdot \mathrm{kg}^{-1}\end{array}$} & \multicolumn{5}{|c|}{$\mathrm{FBG} / \mathrm{mmol} \cdot \mathrm{L}^{-1}$} & \multirow{2}{*}{$\begin{array}{c}\text { INS/ } \\
\mathrm{mU} \cdot \mathrm{L}^{-1}\end{array}$} \\
\hline & & & 7th day & 14th day & 21st day & 28th day & 35 th day & \\
\hline control group & 12 & - & $4.45 \pm 1.2$ & $5.23 \pm 1.4$ & $6.41 \pm 1.3$ & $7.11 \pm 1.5$ & $6.89 \pm 1.3$ & $358.6 \pm 122.4$ \\
\hline model group & 12 & - & $11.33 \pm 2.51^{b}$ & $20.25 \pm 3.10^{b}$ & $18.71 \pm 2.63^{b}$ & $19.14 \pm 2.34^{b}$ & $18.85 \pm 2.25^{b}$ & $115.2 \pm 21.5^{b}$ \\
\hline \multirow{3}{*}{$\begin{array}{l}\text { Melastoma } \\
\text { dodecandrum } \\
\text { ethanol-extract } \\
\text { group }\end{array}$} & 12 & 10 & $11.20 \pm 3.01$ & $18.23 \pm 2.99$ & $16.52 \pm 3.23$ & $15.37 \pm 3.44$ & $13.01 \pm 3.26^{\mathrm{b}, \mathrm{c}}$ & $125.4 \pm 20.7$ \\
\hline & 12 & 20 & $9.77 \pm 3.15$ & $15.32 \pm 3.78$ & $14.61 \pm 4.01^{\mathrm{c}}$ & $12.75 \pm 3.87^{\mathrm{c}}$ & $12.28 \pm 2.99^{\mathrm{b}, \mathrm{d}}$ & $156.8 \pm 39.3^{b, c}$ \\
\hline & 12 & 40 & $10.58 \pm 4.11$ & $13.89 \pm 4.21$ & $13.12 \pm 3.98^{c}$ & $10.62 \pm 4.54^{\mathrm{d}}$ & $10.09 \pm 3.87^{\mathrm{b}, \mathrm{d}}$ & $153.4 \pm 68.5$ \\
\hline control group & 12 & $\begin{array}{l}0.30 \\
\times 10^{-3}\end{array}$ & $11.12 \pm 3.45$ & $17.52 \pm 3.31$ & $13.35 \pm 3.10$ & $11.66 \pm 3.78$ & $10.89 \pm 3.56^{\mathrm{b}, \mathrm{d}}$ & $131.5 \pm 30.8$ \\
\hline
\end{tabular}


TC,TG and LDL-C effects of Melastoma dodecandrum ethanol-extract on type 2 diabetic rats. Compared with the control group, TC, TG and LDL-C levels of model group rats were significantly increased $(P<0.01)$, TG of positive control group was significantly increased $(P<0.05)$. Compared with the model group, TC and LDL-C levels of Melastoma dodecandrum ethanol-extract medium dose group were significantly lower $(P<0.05)$ and TG levels was significantly lower $(P<0.01)$; TG levels of positive control group was significantly lower $(P<0.01)$. Shown in table 3.

Table 3 TC,TG and LDL-C effects of Melastoma dodecandrum ethanol-extract on type 2 diabetic rats ( $\pm \pm s)$

\begin{tabular}{|c|c|c|ccc|}
\hline Groups & $\mathrm{n}$ & $\begin{array}{c}\text { Dose } \\
/ \mathrm{g} \cdot \mathrm{kg}^{-1}\end{array}$ & $\mathrm{TC} / \mathrm{mmol} \cdot \mathrm{L}^{-1}$ & $\mathrm{TG} / \mathrm{mmol} \cdot \mathrm{L}^{-1}$ & $\mathrm{LDL}-\mathrm{C} / \mathrm{mmol} \cdot \mathrm{L}^{-1}$ \\
\hline control group & 12 & - & $1.52 \pm 0.13$ & $0.66 \pm 0.13$ & $0.64 \pm 0.12$ \\
model group & 12 & - & $2.15 \pm 0.10^{\mathrm{b}}$ & $1.63 \pm 0.44^{\mathrm{b}}$ & $1.06 \pm 0.17^{\mathrm{b}}$ \\
$\begin{array}{c}\text { Melastoma } \\
\text { dodecandrum } \\
\text { ethanol-extract } \\
\text { group }\end{array}$ & 12 & 10 & $2.01 \pm 0.47$ & $1.15 \pm 0.39$ & $1.02 \pm 0.27$ \\
$\begin{array}{c}\text { positive control } \\
\text { group }\end{array}$ & 12 & $0.30 \times 10^{-3}$ & $1.01 \pm 0.21$ & $1.06 \pm 0.34^{\mathrm{a}, \mathrm{d},}$ & $1.01 \pm 0.21$ \\
\hline
\end{tabular}

\section{Discussion}

Type 2 diabetic is a metabolic disorders which main feature are elevated blood glucose levels and insulin resistance. Now researchers realized that the pathogenesis are insulin resistance and insulin secretion less which lead to the blood sugar and blood lipid concentration at a high level ${ }^{[1,12]}$. So, the main efficacy of drugs to treatment of type 2 diabetic were decrease blood glucose and regulate blood lipids ${ }^{[8]}$.

Polysaccharide MD 1 component of Melastoma dodecandrum have strong efficacy to scavenge radical and inhibit erythrocyte membrane lipid peroxidation, which have some effects for anti-aging, anti-ulcer and anti-inflammatory, anti-cancer, decrease blood glucose, regulate blood lipids and other pharmacological effects ${ }^{[13]}$.

The experimental results showed that compared with the model group, body weight of Melastoma dodecandrum ethanol-extract of medium dose group rats significantly increased $(P<0.05)$; after administration $28 \mathrm{~d}$, FBG of Melastoma dodecandrum ethanol-extract groups of high dose , medium dose and low dose were significantly lower $(P<0.01$ or 0.05$)$; INS levels of Melastoma dodecandrum ethanol-extract medium dose group were significantly increased $(P<0.05)$; TC and LDL-C levels of Melastoma dodecandrum ethanol-extract medium dose group were significantly lower $(P<0.05)$ and TG levels was significantly lower $(P<0.01)$.

\section{Conclusion}

These results indicated that Melastoma dodecandrum ethanol-extract can effectively promote insulin secretion, improve insulin resistance and decrease blood glucose, regulate blood lipids in type 2 diabetic, it also open ideas to development new hypoglycemic drugs. About its hypoglycemic mechanism and active ingredients to be further research and exploration. 


\section{Acknowledgement}

This work was supported by the National Natural Science Foundation of China (81373725). No potential conflicts of interest were disclosed.

\section{References}

[1] YU Zhi-cheng, LIN Xiu-xiang, SU Jin-qiang, et al. Research Progress on M. dodecandrum Lour. Journal ofAnhui Agri. Sci. 2011.39(27):16557-16559,16702.

[2] LI Li, ZHOU Fang, HUANG Qiong-zhen. Progress of chemical composition and pharmacological effects M. dodecandrum Lour. Journal of Guangxi Tradition Chinese medical university. 2011. 14(1):73-75.

[3] YANG Dan, MA Qing-yun, LIU Yu-qing, et al. Chemical Constituents from Melastoma dodecandrum. Nat Prod Res Dev. 2010. 22: 940-944.

[4] LI Li, ZHOU Fang, LUO Wen-li. Hypoglycemic effect of the aqueous extract from Melastoma dodecandrum Lour on alloxan-induced diabetic mice. Strait Pharmaceutica1 Journal. 2008. 20(12): 22-23.

[5] LI Li, LUO Ze-ping, YANG Xiu-fen, et al. Blood sugar effects of Melastoma dodecandrum ethanol-extract on diabetic mice. Chinese Journal of Gerontology. 2014. 34: 3091-3093.

[6] Ministry of Science of People's Republic of China . Guidance Note for Care of Laboratory Animals[Z]. 2006-09-30.

[7] CHEN Yong-xin, WEI Jin-bin. Research advance of type 2 diabetes complications rat models induced by streptozotocin. CHINESE JOURNAL OF COMPARATIVE MEDICINE. 2013, 23(3): 63-66.

[8] WANG Gui-hong, ZHU Huan, Wu Yong. Hypoglycemic and Hypolipidemic Effects of Xiaoke Capsules on Type 2 Diabetic Rats. Chinese Journal of Experimental Traditional Medical Formulae. 2014. 20(17):171-174.

[9] WU Zhi-qian, HAO Gai-mei, XUE Xiao-xing, et a1. Research on the effect of Gegenqinlian Decoction on type 2 diabetic model. Global Traditional Chinese Medicine. 2014.7(3):161-167.

[10] PAN Qiu, ZHAO Hui-hui, CHEN Jian-xin, et al. Research the Characterization and characteristics of the syndrome on type 2 diabetic rats. China Journal of Traditional Chinese Medicine and Pharmacy. 2011. 26(4): 683-685.

[11] GAO Xiu-ying, ZHOU Ying-sheng. Review of mouse and rat models for type 2 diabetes mellitus. ACTA LABORATORIUM ANIMALIS SCIENTIA SINICA. 2014.22(4):71-76.

[12] Yang W, Lu J, Weng J, et a1. Prevalence of diabetes among men and women in China. THE NEW ENGLAND JOURNAL OF MEDICINE. 2010. 362(12): 1090-1101.

[13] GU Cheng-ying, WANG Ai-hua, ZENG Yi-peng, et a1. Influence of different kind of dysiipidaemia on complication in type 2 diabetic patients. China Journal of Modern Medicine. 2009, 19(8):1253-1256,1259. 